\title{
Early Surgical Correction of Transplant Renal Artery Stenosis (Tras)-A Case Report
}

\author{
M. P. Vettath ${ }^{1 *}$, A. V. Kannan ${ }^{2}$, M. Ashish ${ }^{3}$, N. Sajith ${ }^{4}$ \\ ${ }^{1}$ Chairman, Cardiothoracic \& Vascular Surgery, Meitra Hospital, Kozhikode, Kerala, India \\ ${ }^{2}$ Chief Cardiac Anaesthesiologist, Meitra Hospital, Kozhikode, Kerala, India \\ ${ }^{3}$ Chairman, Department of Cardiology, Meitra Hospital, Kozhikode, Kerala, India \\ ${ }^{4}$ HOD, Department of Nephrology, Aster MIMS, Kozhikode, Kerala, India \\ Email: *murali.vettath@gmail.com
}

How to cite this paper: Vettath, M.P., Kannan, A.V., Ashish, M. and Sajith, N. (2019) Early Surgical Correction of Transplant Renal Artery Stenosis (Tras)-A Case Report. Surgical Science, 10, 164-168. https://doi.org/10.4236/ss.2019.105020

Received: April 11, 2019

Accepted: May 26, 2019

Published: May 29, 2019

Copyright $\odot 2019$ by author(s) and Scientific Research Publishing Inc. This work is licensed under the Creative Commons Attribution International License (CC BY 4.0).

http://creativecommons.org/licenses/by/4.0/

\begin{abstract}
Saphenous vein graft (SVG) bypass of the renal artery from the aorta has been well documented, though bypass of the internal iliac artery to the individual renal arteries is not yet described. We herewith present a case of early TRAS detected 6 hours after a successful renal transplant. Renal angiography showed complete stenosis of the internal iliac to renal artery anastomosis. Percutaneous transplant artery angioplasty was attempted, but was not successful; hence the surgical correction of the same was done. This is to demonstrate the use of saphenous vein bypass of anastomotic obstruction of the previous anastomosis, in case of short renal artery.
\end{abstract}

\section{Keywords}

Transplant Renal Artery Stenosis, Saphenous Vein Graft, Renal Angiography, Percutaneous Transluminal Angioplasty (PTA)

\section{Introduction}

Transplant renal artery stenosis (TRAS) is an increasingly recognized complication of kidney transplantation. It represents a potentially reversible cause of hypertension and allograft dysfunction. The incidence varies from $1 \%$ to $23 \%$ depending on the center, the definition of TRAS, and the intensity of screening done. The detected incidence of TRAS increased from $2.4 \%$ to $12.4 \%$ at one center with the introduction of color Doppler ultrasonography. The highest incidence (23\%) was found in a series of patients undergoing angiography.

Surgical techniques for repair of TRAS have included resection and revision of 
the anastomosis, renal artery patch angioplasty, localized endarterectomy, and renal artery bypass with either recipient saphenous vein or ipsilateral hypogastric artery [1] [2] [3] [4]. We present a double saphenous vein bypass of the anastomotic site, without disturbing the anastomosis in case of short dual renal arteries.

\section{Case Report}

We present a 36-year-old young robust male, who was on dialysis for the last 6 years who underwent renal transplant. The only unusual finding during the transplant was that the donor kidney (patient's own sister) had two renal arteries and was short. Hence they were implanted onto the internal iliac artery as an end to end with a double barrel technique. After surgery, patient had passed 200 $\mathrm{ml}$ of urine, before reaching the transplant ICU.

After reaching the ICU, there was decreasing amount of urine for a couple of hour. He was then taken up for renal angiogram which showed total obstruction of the right internal iliac at the level of the anastomosis (Figure 1). Immediately a guide wire was passed and a percutaneous renal angiography and balloon angioplasty was attempted, which just showed trickle of flow and thrombus in the renal artery lumen and the internal iliac (Figure 2). In view of the criticality of the situation and need to salvage the transplant kidney, it was planned to re-explore the abdomen the same night.

On exploring the anastomotic site though there was pulsation at the site, but a pressure gradient of $40 \mathrm{~mm}$ across the anastomosis was noticed. Hence it was planned to bypass the anastomosis without touching the first anastomosis, using a saphenous vein graft. As both the anastomosed renal arteries were short and only $3 \mathrm{~mm}$ in diameter. A small segment of saphenous vein was harvested from the leg and was used as two grafts to anastomose between the internal iliac artery and the two renal arteries separately after removing the thrombus from both the lumens. Good flow noticed in the grafts and after closure, the patient was shifted to transplant ICU. He started making urine after one day. A renal angiogram was performed on the next day which showed good flow in the renal arteries (Figure 3). After one week he was shifted to the ward as he had good urine output and his renal parameters improved.

\section{Discussion}

TRAS is a known complication of renal transplant, which could be acute or seen after years of transplant. It is an important and treatable cause of hypertension and graft dysfunction in renal allograft recipients. Surgical treatment is reserved for lesions that are not amenable to percutaneous transluminal angioplasty (PTA) or for recurrence after PTA. Various surgical options for reconstruction of the transplant renal artery exist, although no single technique has been demonstrated to be superior [5].

Transplant renal artery stenosis (TRAS) is the most frequent vascular complication in renal transplantation with an incidence varying between $1 \%$ and 


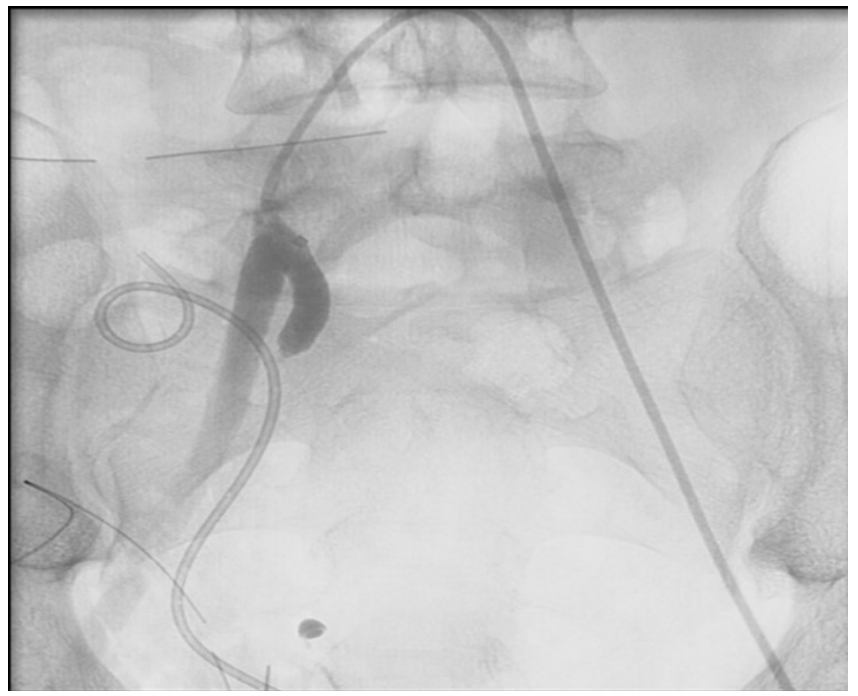

Figure 1. Angiogram showing no flow into the renal artery from the external iliac artery.

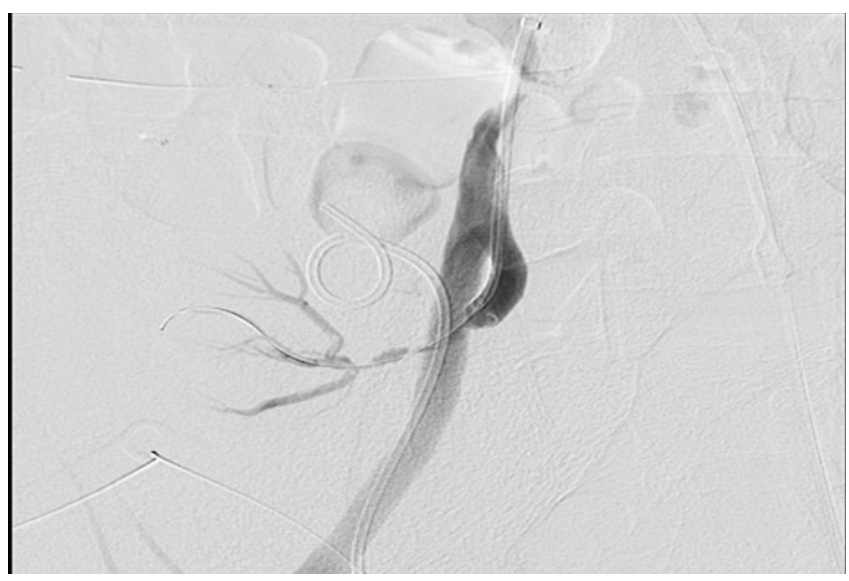

Figure 2. Angiogram after angioplasty of the right external iliac showing low flow through the stenotic renal artery anastomosis.

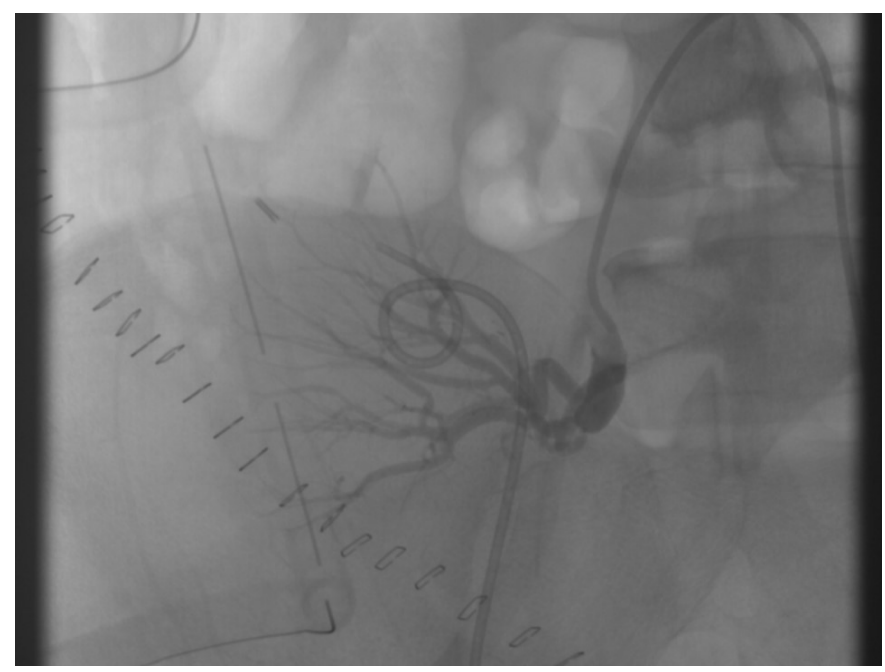

Figure 3. Showing the saphenous vein grafts bypassing the stenotic segment from external iliac artery into the renal artery thereby perfusing the kidney. 
25\% [6] [7] [8] [9]. The etiology and management of TRAS vary by location relative to the anastomosis, and it is therefore classified relative to this structure. TRAS can occur proximal to the anastomosis (perianastomotic, at the anastomosis, or within the donor artery (postanastomotic). TRAS may be a consequence of faulty surgical techniques, arterial damage during donor nephrectomy or kidney perfusion, kinking and compression of the renal artery, size discrepancy between donor and recipient renal arteries, and chronic rejection [10].

The early detection of the stenosis in the immediate post-operative phase and modifying the surgical techniques as needed for the particular patient would go a long way in saving the transplanted kidney.

\section{Conclusion}

We herewith present this interesting case of TRAS, surgically corrected using a double saphenous vein graft used as a conduit to revascularize the transplanted kidney. The novelty of this unusual technique, which was used as last resort in a case of short multiple renal arteries is highlighted as the first anastomosis was left alone and this SVG was used as a bypass over the previous anastomosis is highlighted.

\section{Conflicts of Interest}

The authors declare no conflicts of interest regarding the publication of this paper.

\section{References}

[1] Fervenza, F.C., Lafayette, R.A., Alfrey, E.J., et al. (1998) Renal Artery Stenosis in Kidney Transplants. American Journal of Kidney Diseases, 31, 142-148. https://doi.org/10.1053/ajkd.1998.v31.pm9428466

[2] Wong, W., Fynn, S.P., Higgins, R.M., et al. (1996) Transplant Renal Artery Stenosis in 77 Patients: Does It Have an Immunological Cause? Transplantation, 61, 215-219. https://doi.org/10.1097/00007890-199601270-00009

[3] Lacombe, M. (1975) Arterial Stenosis Complicating Renal Allotransplantation in Man: A Study of 38 Cases. Annals of Surgery, 181, 283-288. https://doi.org/10.1097/00000658-197503000-00007

[4] Shames, B.D., et al. (2003) Surgical Repair of Transplant Renal Artery Stenosis with Preserved Cadaveric Iliac Artery Grafts. Annals of Surgery, 237, 116-122. https://doi.org/10.1097/00000658-200301000-00016

[5] Chan, H.W., Ho, Y.W., Chan, C.M., Yiu, T.F., Tong, M.K. and Wong, P.H. (1995) Treatment of Anastomotic Ostial Allograft and Renal Artery Stenosis with the Palmazstent. Transplantation, 59, 436-439.

[6] Loubeyre, P., Cahen, R., Grozel, F., et al. (1996) TRANSPLANT RENAL ARTERY STENOSIS: Evaluation of Diagnosis with Magnetic Resonance Angiography Compared with Color Duplex Sonography and Arteriography. Transplantation, 62, 446-450. https://doi.org/10.1097/00007890-199608270-00004

[7] Sutherland, R.S., Spees, E.K., Jones, J.W. and Fink, D.W. (1993) Renal Artery Stenosis after Renal Transplantation: The Impact of the Hypogastric Artery Anastomosis. 
The Journal of Urology, 149, 980-985.

https://doi.org/10.1016/S0022-5347(17)36273-0

[8] Sankari, B.R., Geisinger, M., Zelch, M., Brouhard, B., Cunningham, R. and Novick, A.C. (1996) Post-Transplant Renal Artery Stenosis: Impact of Therapy on Long-Term Kidney Function and Blood Pressure Control. The Journal of Urology, 155, 1860-1864. https://doi.org/10.1016/S0022-5347(01)66030-0

[9] Kauffman, H.M., Sampson, D., Fox, P.S., Doyle, T.J. and Maddison, F.E. (1977) Prevention of Transplant Renal Artery Stenosis. Surgery, 81, 161-167.

[10] Tilney, N.L., Rocha, A., Strom, T.B. and Kirkman, R.L. (1984) Renal Artery Stenosis in Transplant Patients. Annals of Surgery, 199, 454-460.

https://doi.org/10.1097/00000658-198404000-00013 